\title{
Diagnostic and therapeutic impact of whole body positron emission tomography using fluorine-18-fluoro-2-deoxy-D-glucose in children with chronic granulomatous disease
}

\author{
T Güngör, I Engel-Bicik, G Eich, U V Willi, D Nadal, J P Hossle, R A Seger, H C Steinert
}

Divisions of

Immunologyl

Haematology/Oncologyl

BMT and Infectious

Diseases, University

Children's Hospital,

Zürich, Switzerland

T Güngör

D Nadal

J P Hossle

R A Seger

Division of Paediatric Radiology, University Children's Hospital G Eich

U V Willi

Department of Radiology, Division of Nuclear Medicine, University Hospital, Zürich, Switzerland I Engel-Bicik

H C Steinert

Correspondence to: Dr Güngör

Tayfun.Guengoer@kispi. unizh.ch

Accepted 11 June 2001

\begin{abstract}
Aims-To compare whole body positron emission tomography (PET) using fluorine-18-fluoro-2-deoxy-D-glucose (FDG) with computed tomography (CT) in detecting active infective foci in children with chronic granulomatous disease. Methods-We performed 22 whole body FDG PET studies in seven children with $X$ linked $(n=6)$ or autosomal recessive $(n=1)$ CGD. All had clinical signs of infection and/or were evaluated prior to bone marrow transplantation (BMT). Nineteen PET studies were also correlated with chest and/or abdominal CT. All PET scans were interpreted blinded to the CT findings. Diagnoses were confirmed histologically and bacteriologically.

Results-We detected 116 lesions in 22 FGD PETs and 126 lesions on 19 CTs. Only two of the latter could be classified reliably as active lesions by virtue of contrast enhancement suggesting abscess formation. PET excluded 59 lesions suspicious for active infection on CT and revealed 49 infective lesions not seen on CT. All seven active infective lesions were identified by PET, allowing targeted biopsy and identification of the infective agent followed by specific antimicrobial treatment, surgery, or subsequent BMT.

Conclusions-Identification of infective organisms is more precise if active lesions are biopsied. CT does not discriminate between active and inactive lesions. Whole body FDG PET can be used to screen for active infective lesions in CGD patients. (Arch Dis Child 2001;85:341-345)
\end{abstract}

Keywords: infection; immunodeficiency; computed tomography; granulomatous disease; positron emission tomography; granuloma

Chronic granulomatous disease (CGD) is an $\mathrm{X}$ linked $(70-80 \%)$ or autosomal recessively inherited $(20-30 \%)$ primary immunodeficiency (estimated incidence 1 in 20000 to 1 in 250000 live births) with complete absence or malfunction in phagocytes of the plasma membrane associated enzyme complex nicotinamide adenine dinucleotide phosphate (NADPH) oxidase. ${ }^{1}$ Deficiency of this oxidase causes notable diminution or absence of the phagocytic respiratory burst and superoxide radicals, resulting in defective killing of catalase positive bacteria and fungi. These organisms survive phagocytosis, so are not eliminated. Granuloma formation takes place such that multiorgan granulomatous abscesses, including pyoderma, lymphadenitis, pneumonia, osteomyelitis, oesophagitis, colitis, and urinary tract infections ensue as major clinical manifestations. ${ }^{2}$ In some CGD patients the clinical picture is characterised by exuberant and persistent granuloma formation resulting in intestinal or genitourinary obstruction, functional impairment of vital organs, and severe disability. ${ }^{1}$ Some of these inflammatory complications respond to systemic anti-inflammatory treatment. ${ }^{1-3}$

The main organisms responsible for infections are catalase positive bacteria, for example, Staphylococcus, Burkholderia cepacia, Nocardia, Mycobacteria, Serratia, Klebsiella, Pseudomonas species, and fungi, especially Aspergillus species $^{4}$ but also Candida and Paecilomyces. ${ }^{5}$ Despite prophylaxis with cotrimoxazole and itraconazole, ${ }^{6}$ or $\gamma$ interferon, ${ }^{7}$ CGD patients are at risk of contracting aspergillosis several times in their life. ${ }^{6}$ Currently, the probability of succumbing to infection or irreversible organ damage is about $2-5 \%$ per patient per year. ${ }^{5}$

Established treatment for CGD patients with severe infections or severe organ damage is granulocyte infusions or HLA identical bone marrow transplantation (BMT). ${ }^{8}$ Prior to BMT it is mandatory to identify all active sites of infections including those clinically silent, because aplasia and immunosuppression might threaten the outcome of transplantation before engraftment is fully established.

One imaging modality with the potential to screen for active infective lesions is whole body positron emission tomography (PET) with fluorine-18-fluoro-2-deoxy-D-glucose (FDG). FDG uptake is increased physiologically in brain, heart, kidneys, and bladder. Excellent FDG uptake into active inflammatory and infective lesions caused by the higher glucose metabolism of activated leucocytes, granulocytes, and macrophages has been described. ${ }^{9-14}$

We designed this prospective study to investigate the diagnostic value of whole body FDG PET when compared with CT in patients with CGD, especially before HLA identical bone marrow transplantation or surgery.

Patients and methods

PATIENTS

We performed 22 examinations on seven boys (aged 5-16 years, mean 13). Six had an X 
chromosomal inheritance (proven gp91-phox mutation) and one, not genetically characterised (patient 6), is considered to have autosomal recessive CGD. All mutation analyses were performed in our laboratory. The patients were on antimicrobial prophylaxis with either cotrimoxazole $(36 \mathrm{mg} / \mathrm{kg} /$ day) or ciprofloxacin (20-25 mg/kg/day). In addition all received antifungal prophylaxis with itraconazole (5-10 $\mathrm{mg} / \mathrm{kg} /$ day); $\gamma$ interferon prophylaxis was not given. Eight PET studies were carried out for diagnostic purposes, as the patients had clinical signs of refractory infection with raised inflammatory markers, or were being considered for HLA identical BMT. Fourteen studies were performed as follow up evaluation after antimicrobial therapy, surgery, or BMT. BMT was performed according to a previously published protocol ${ }^{8}$ with busulfan $(16 \mathrm{mg} / \mathrm{kg})$ and cyclophosphamide $(200 \mathrm{mg} / \mathrm{kg}$ ) (patients 3, 4, 5). In one case (patient 6) fludarabine $\left(150 \mathrm{mg} / \mathrm{m}^{2}\right)$ was given instead of cyclophosphamide.

CT SCANNING

Nineteen patients also underwent CT of the chest or abdomen, or both, performed on a PQ2000 scanner (Picker International, Cleveland, Ohio) using standard intravenous contrast enhanced protocols.

PET SCANNING

To suppress myocardial glucose utilisation, patients were asked to fast for at least four hours before FDG application. FDG PET scanning was performed with a commercially available instrument (Advance, GE Medical System, Milwaukee, Wisconsin) with the whole body mode implemented as standard software. In this mode, the scanner acquired two dimensional data over an axial field of view of 14.6 $\mathrm{cm}$. Emission and transmission scans were obtained with an acquisition time of five minutes per field of view. FDG was produced in our own radiopharmaceutical laboratory. Transmission scanning began immediately after the administration of at least $130 \mathrm{MBq}$ of FDG. Emission scanning followed 40 minutes after administration of FDG. The acquired data were reconstructed by using standard back projection techniques in axial sections and reformatted into coronal and sagittal views.

The PET scans were performed on the same day or within 22 (mean $1 \pm 8$ ) days of the corresponding CT examination. In three studies, only PET data were used for follow up of the therapeutic management.

DATA ANALYSIS

PET scans were interpreted blinded to the CT results but not to the clinical data. Visual grading was performed according to a four level scale (0, no FDG uptake, definitely normal; 1 , faint FDG uptake, probably normal; 2, intermediate FDG uptake, probably abnormal; 3, high FDG uptake, definitely abnormal). The lesions were counted by regions and scores of 2 and 3 were considered to correspond to active lesions, a score of 1 to chronic lesions. PET diagnoses were confirmed by biopsies (open lung biopsy, percutaneous liver biopsy, endoscopic gastric biopsy) and microbial cultures.

\section{Results}

IMAGING

We detected 116 lesions on 22 FDG PET examinations (table 1 ). Of these, 91 were considered active (score 2: 42 lesions, score 3: 49 lesions), and 25 as chronic (score 1). Of the chronic lesions (patients 1 and 5), 23 remained unchanged during follow up studies. In patient 1, two abdominal lesions were reactivated during follow up but disappeared after specific treatment was initiated (table 2). FDG PET detected 49 new lesions (42 possibly active, seven chronic), which were mainly located in the head/neck region, liver, stomach, or gastrointestinal tract (table 1).

We detected 126 lesions on 19 CT studies, of which only two could reliably be classified as active because of visible abscess formation and contrast enhancement. Fifty nine lesions, suspicious for acute infection by CT, were classified chronic because of absent FDG uptake on PET. Sixty seven granulomas were observed on either PET or CT, allowing discrimination of 49 active and 18 chronic lesions.

CLINICAL COURSE

In all patients, active lesions were biopsied and cultures taken for infective agents (PET scores 2 and 3 ). In all patients the responsible organism could be identified: Actinomyces naeslundii, Paecilomyces variotii, Aspergilus nidulans, Aspergillus fumigatus $(\mathrm{n}=2)$, Candida species, and Staphylococcus aureus. Treatment was with lipophilic antibiotics (according to the susceptibility pattern) or intravenous liposomal amphotericin B (Ambisome, $3-5 \mathrm{mg} / \mathrm{kg}$ ). In five patients HLA identical BMT was performed; four were cured but one died as as result of graft versus host disease, grade IV. Table 2 summarises the infective organisms and the clinical course of patients 1 to 7 . In patient 1 (fig 1), biopsy from an active lesion, detected by PET, showed Actinomyces naeslundii. After 12 months of intravenous antibiotic treatment, four consecutive PET studies showed slow improvement of the lung lesions. After the antibiotics were switched to the oral route, recurrent fever developed and new active lesions developed in lung and pleura. Following pleurectomy and granulocyte infusions, two repeated PET studies showed only chronic lesions.

\section{Discussion}

CT imaging is an established means to localise site and extent of infective foci in CGD patients. However, it is often unreliable in differentiating active from chronic lesions because of lack of definitive discriminating CT imaging signs. For example, in lymphadenopathy, the size, number, and volume of the affected lymph nodes are considered indicators of active infection. However, the only definite sign for acute infection is abscess formation and contrast enhancement. ${ }^{15}$ 
Table 1 Granulomatous lesions in patients

\begin{tabular}{llcccc}
\hline Lesions & Examinations (n) & Possibly active & Active & Chronic & Total \\
\hline PET & 22 & 42 & 49 & 25 & 116 \\
CT & 19 & 124 & 2 & & 126 \\
Concordant (CT/PET) & & 49 & 18 & 67 \\
Lesions only found in CT & 59 & & 7 & 59 \\
Lesions only found in PET & 42 & 49 & 25 & 175 \\
Total CT + PET & 101 & 49 & \\
\hline
\end{tabular}

PET is a non-invasive, functional imaging method, which can be carried out as a whole body procedure. It requires access to a cyclotron that produces FDG, which limits its widespread use. Small children and infants may need sedation during the imaging procedure, which was not necessary in our group of patients.

In combination with FDG, PET appears to be suitable for the identification of active infective lesions by high FDG uptake into inflammatory tissue. ${ }^{13}{ }^{14}$ Inactive lesions, however, such as pulmonary granulomas, do not show raised FDG uptake because of low glucose metabolism. ${ }^{16}$

It is believed that the glucose dependent respiratory burst of the phagocytic cells is responsible for this FDG uptake. In patients with CGD, however, the deficiency of NADPH oxidase causes a notable diminution or absence of this respiratory burst. Therefore, accumulation of FDG in active infective lesions in patients with CGD is caused by other mechanisms, probably the incorporation of FDG into phagocytic cells during ATP generation. Phagocytosis itself is energy dependent, and would thereby increase glucose or FDG consumption. An alternative explanation might be that non-NADPH oxidase related killing mechanisms are additionally contributing to increased glucose consumption. ${ }^{17}$
Both hypotheses could explain the fact that tissues with active FDG accumulation contain freshly phagocytosed infective agents responsible for acute inflammation.

In our series, PET excluded 59 lesions suspicious of active infection on CT imaging, while CT imaging alone showed 126 lesions, of which only two could be classified reliably as active. The fact that CT imaging is limited to the area of interest so that distant and clinically inconspicuous sites may not be imaged is supported by our finding that 49 additional infective lesions could be depicted by whole body PET.

These lesions were mainly located in the head and neck region, regions not routinely imaged by CT. Moreover, in the abdomen, mainly the stomach and intestines, PET was able to localise additional active foci, not detected on CT imaging or sonography. These lesions corresponded to granulomatous gastritis or colitis. Here, FDG PET seemed to be more sensitive than CT scanning, as has been shown previously in ulcerative colitis. ${ }^{13}$ This can be of great clinical value, especially to substantiate a decision for intestinal endoscopy and tissue biopsy as performed in patient 6 before BMT or to monitor anti-inflammatory and anti-infective therapy.

In patient 1 (no suitable BMT donor available) FDG PET and serial biopsies helped to show that Actinomyces naeslundii persisted for years with several relapses despite targeted antibiotic therapy. In this context, FDG PET examinations clearly helped to discriminate between active and inactive lesions (fig 1). Finally, granulocyte infusions and pleurectomy were able to control chronic Actinomyces infection. This clinical impression was again supported by follow up FDG PET examinations.

Table 2 Clinical indications for diagnostic FDG PET studies

\begin{tabular}{|c|c|c|c|c|c|c|c|}
\hline Patient & $\begin{array}{l}\text { Age } \\
(y)\end{array}$ & $\begin{array}{l}\text { Clinical } \\
\text { indication }\end{array}$ & $P E T$ reading & Biopsy & Organism & Clinical impact of PET & Follow up \\
\hline \multirow[t]{3}{*}{1} & \multirow[t]{3}{*}{5} & $\begin{array}{l}\text { Pneumonia, } \\
\text { fever }\end{array}$ & $\begin{array}{l}\text { Active lesions } \\
\text { (lung/mediastinum) } \\
\text { Chronic lesions (abdomen) }\end{array}$ & $\begin{array}{l}\text { Yes } \\
\text { (lung) }\end{array}$ & Act naeslundii & $\begin{array}{l}\text { Adapted antimicrobial } \\
\text { therapy according to } \\
\text { resistance pattern }\end{array}$ & $\begin{array}{l}4 \text { PETs, slow improvement, but } \\
\text { relapse }\end{array}$ \\
\hline & & \multirow[t]{2}{*}{ Fever } & \multirow[t]{2}{*}{$\begin{array}{l}\text { Active lesions in the left lung, } \\
\text { pleura, gut }\end{array}$} & \multirow[t]{2}{*}{$\begin{array}{l}\text { Yes } \\
\text { (lung, } \\
\text { pleura) }\end{array}$} & \multirow[t]{2}{*}{ Act naeslundii } & \multirow{2}{*}{$\begin{array}{l}\text { Surgical intervention with } \\
\text { pleurectomy after ineffective } \\
\text { antimicrobial treatment, } \\
\text { granulocyte infusions }\end{array}$} & $\begin{array}{l}4 \text { PETs, slow improvement, but } \\
\text { relapse in pleural effusion }\end{array}$ \\
\hline & & & & & & & $\begin{array}{l}\text { After pleurectomy at last follow up ( } 1 \\
\text { year later) chronic non-active lesions }\end{array}$ \\
\hline 2 & 16 & Prior BMT & $\begin{array}{l}\text { Active lesions in the lung, neck, } \\
\text { and gut }\end{array}$ & $\begin{array}{l}\text { Yes } \\
\text { (lung) }\end{array}$ & Paec variotii & $\begin{array}{l}\text { Antifungal treatment with } \\
\text { liposomal amphotericin B }\end{array}$ & $\begin{array}{l}2 \text { PETs, refused continuation of } \\
\text { antifungal therapy, BMT omitted }\end{array}$ \\
\hline 3 & 8 & Prior BMT & $\begin{array}{l}\text { Active lesions (lung, } \\
\text { mediastinum, bone, and } \\
\text { abdomen) }\end{array}$ & $\begin{array}{l}\text { Yes } \\
\text { (lung) }\end{array}$ & Asp nidulans & $\begin{array}{l}\text { Antifungal treatment with } \\
\text { liposomal amphotericin B, } \\
\text { BMT }\end{array}$ & $1 \mathrm{PET}$, cured \\
\hline 4 & 16 & Prior BMT & Active lesion (lung) & $\begin{array}{l}\text { Yes } \\
\text { (lung) }\end{array}$ & Asp fumigatus & $\begin{array}{l}\text { Persisting active lesion, } \\
\text { liposomal amphotericin B, } \\
\text { granulocyte transfusions } \\
\text { during BMT }\end{array}$ & $\begin{array}{l}\text { Diseased (severe GVHD IV), autopsy } \\
\text { refused }\end{array}$ \\
\hline 5 & 15 & Prior BMT & Suspected active lesion (lung) & $\begin{array}{l}\text { Yes } \\
\text { (lung) }\end{array}$ & Asp fumigatus & $\begin{array}{l}\text { Active lesion, BMT } \\
\text { performed, liposomal } \\
\text { amphotericin B } \\
\text { administration }\end{array}$ & 1 PET, cured \\
\hline 6 & 16 & Prior BMT & Gastric active lesion & $\begin{array}{l}\text { Yes } \\
\text { (gastric) }\end{array}$ & $\begin{array}{l}\text { Candida } \\
\text { species }\end{array}$ & $\begin{array}{l}\text { Antifungal prophylaxis with } \\
\text { liposomal amphotericin B }\end{array}$ & 1 PET, cured \\
\hline 7 & 16 & $\begin{array}{l}\text { Raised } \\
\text { CRP, BSR } \\
\text { (chron.) }\end{array}$ & Active lesion in the liver & $\begin{array}{l}\text { Yes } \\
\text { (liver) }\end{array}$ & Staph aureus & $\begin{array}{l}\text { Drainage, antibiotic } \\
\text { treatment }\end{array}$ & $1 \mathrm{PET}$, cured \\
\hline
\end{tabular}



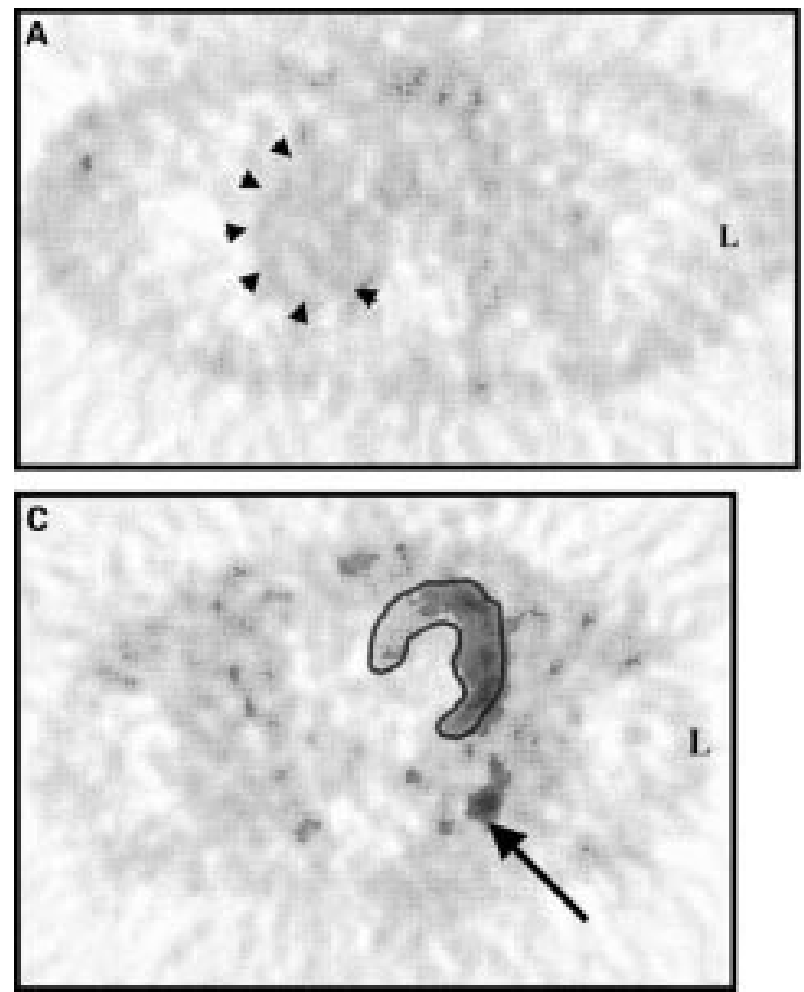
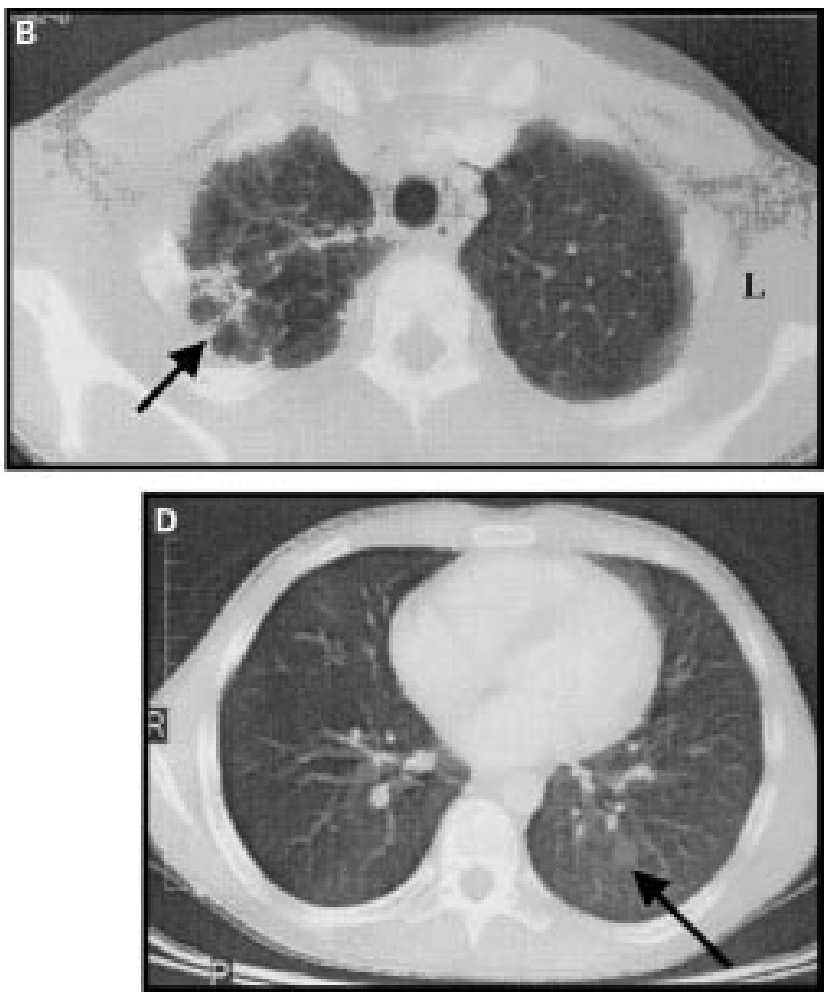

Figure 1 Corresponding axial FDG PET $(A, C)$ and $C T(B, D)$ slices of inactive $(A, B)$ and active $(C, D)$ infective lesions $($ Actinomyces naeslundii) of patient 1. The heart is outlined.

In another patient with non-specific complaints (patient 7) FDG PET helped to find the infective focus in the liver, especially when conventional imaging techniques (ultrasonography) failed to do so. A follow up PET examination after antibiotic therapy and surgical drainage indicated eradication of the responsible microorganism ( $S$ aureus) in this patient.

Five of seven patients were in preparation for HLA identical BMT. FDG PET was requested in these patients to localise possible infective lesions, which might be exacerbated during the process of BMT (patients $3,4,5,6$ ). In an earlier report, ${ }^{8}$ we were able to show high FDG uptake in active infective lesions of a CGD patient with pulmonary aspergillosis and complete resolution of all such lesions following successful BMT, again proven by FDG PET. Allogeneic HLA identical BMT, which is a curative treatment option, has to be contrasted to conventional treatment with a probability for succumbing to infection or irreversible organ damage of about $2-5 \%$ per patient per year, even when patients are on the best prophylactic regimens. ${ }^{5}$ Since 1976, HLA identical BMT has therefore been used in over 20 CGD patients with excellent results, if the patient was not overtly infected at time of BMT (success rate $>95 \%)$. ${ }^{128} 818$

Before BMT, methods are needed to obtain a complete survey of possibly active sites of infection all over the body in order to eradicate them before cytotoxic drugs are started. Early identification of the responsible microorganism also helps to avoid prolonged treatment with toxic empirical antibiotic and antifungal drugs, which can be followed by irreversible organ damage, for example, renal insufficiency after long term amphotericin B treatment. ${ }^{2}$

Tissue biopsies are needed for identification and susceptibility testing, because blood cultures and bronchoalveoar lavages frequently remain negative. ${ }^{2}$ When multiple granulomas are present, it is difficult to select the optimal biopsy site on the basis of CT scans alone. In our series, FDG PET helped to discriminate between 49 active and 18 chronic granulomas of 67 lesions concordantly observed on PET and CT.

These active lesions were biopsied in all BMT candidates (patients 2-6) and microorganisms could be cultured in all of them. In four of five (patients 3-6), targeted treatment helped to control these microorganisms during aplasia and periods of functional $\mathrm{T}$ cell insufficiency.

In all three successfully transplanted CGD patients, negative follow up PET examinations helped to stop antifungal and antibiotic prophylactic treatment early enough to prevent toxic drug related organ damage (for example, patient 3).

For ethical reasons not all lesions considered to be active on PET scan were biopsied. Thus, we are unable to prove that all of these lesions contained infective organisms. However, all cultures from biopsied lesions judged as active on PET scan grew microorganisms.

Ideally, the measurement of distribution and activity of granulomas by whole body FDG PET should be combined with CT imaging for precise anatomic localisation, both taken together to determine the optimal biopsy site. The fact that we could identify infective agents 
in all CGD patients and initiate successful antimicrobial therapy, surgery, and BMT in the majority of them supports our opinion that FDG PET is a step forward in refining the clinical management of this disorder.

1 Segal BH, Leto TL, Gallin JI, et al. Genetic, biochemical, and clinical features of chronic granulomatous disease. Medicine 2000;79:170-200.

2 Seger R, Ezekowitz R. Treatment of chronic granulomatous disease. Immunodeficiency 1994;5:113-30

3 Rosh JR, Tang HB, Mayer L, et al. Treatment of intractable gastrointestinal manifestations of chronic granulomatous gastrointestinal manifestations of chronic granulom
disease with cyclosporine. J Pediatr 1995;126:143-5.

disease with cyclosporine. F Pediatr 1995;126:143-5.
4 Fischer A, Segal AW, Seger RA, et al. The management of chronic granulomatous disease. Eur f Pediatr 1993;152: $896-9$

5 Winkelstein JA, Marino MC, Johnston RB, et al. Chronic granulomatous disease. Report on a national registry of 368 patients. Medicine 2000;79:155-69.

6 Mouy R, Veber C, Blanche S, et al. Long-term itraconazole prophylaxis against Aspergillus infections in thirty-two patients with chronic granulomatous disease. $\mathcal{F}$ Pediatr 1994;125:998-1003.

7 Weening R, Leitz G, Seger RA. Recombinant human interferon-gamma in patients with chronic granulomatous disease-European follow up study. Eur 7 Pediatr 1995;154: 295-8.

8 Ozsahin $\mathrm{H}$, von Planta M, Muller I, et al. Successful treatment of invasive aspergillosis in chronic granulomatous disease by bone marrow transplantation, granulocyte colony-stimulating factor-mobilized granulocytes, and liposomal amphotericin-B. Blood 1998;92:2719-24.
9 Hawkins RA, Hoh C, Glaspy J, et al. The role of positron emission tomography in oncology and other whole-body emission tomography in oncology and other
applications. Semin Nucl Med 1992;22:268-84

10 Reske SN, Bares R, Bull U, et al. Clinical value of positron emission tomography (PET) in oncologic questions: results of an interdisciplinary consensus conference. Schirmherrschaft der Deutschen Gesellschaft for Nuklearmedizin. Nuklearmedizin 1996;35:42-52.

11 Sugawara Y, Braun DK, Kison PV, et al. Rapid detection of human infections with fluorine-18 fluorodeoxyglucose and positron emission tomography: preliminary results. Eur $\mathcal{F}$ pusitron emission tomograph:

12 Bakheet SM, Powe J, Ezzat A, et al. F-18-FDG uptake in tuberculosis. Clin Nucl Med 1998;23:739-42.

13 Bicik I, Bauerfeind P, Breitbach T, et al. Inflammatory bowel disease activity measured by positron-emission tomography. Lancet 1997;350:262.

14 Peters AM. The use of nuclear medicine in infections. $\mathrm{Br} F$ Radiol 1998;71:252-61.

15 Lal NR, Kazerooni EA, Bree RL. Development and implementation of an appropriateness guideline for use of CT in cases of suspected intrababominal abscess. Acad Radiol 2000;7:711-16.

16 Gupta N, Gill H, Graeber G, et al. Dynamic positron emission tomography with F-18 fluorodeoxyglucose imaging in differentiation of benign from malignant lung/mediastinal lesions. Chest 1998;114:1105-11.

17 Odell EW, Segal AW. Killing of pathogens associated with chronic granulomatous disease by the non-oxidative microbicidal mechanisms of human neutrophils. $7 \mathrm{Med}$ Microbiol 1991;34:129-35.

18 Leung $\mathrm{T}$, Chik $\mathrm{K}, \mathrm{Li} \mathrm{C}$, et al. Bone marrow transplantation for chronic granulomatous disease: long-term follow-up and review of literature. Bone Marrow Transplant 1999;24: $567-70$.

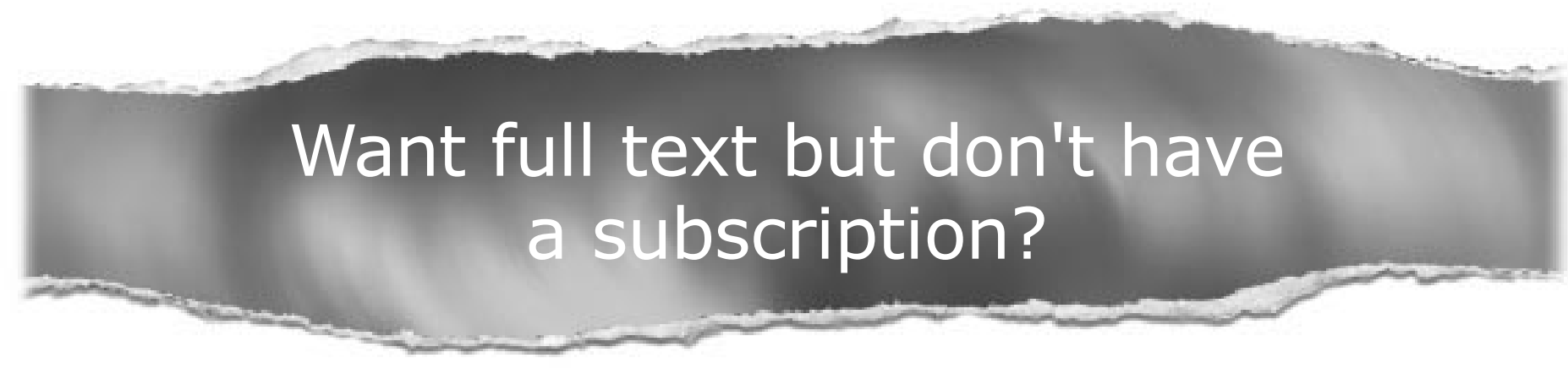

Pay per view

For just $\$ 8$ you can purchase the full text of individual articles using our secure online ordering service. You will have access to the full text of the relevant article for 48 hours during which time you may download and print the pdf file for personal use.

www.archdischild.com 